UNDERGRADUATE RESEARCH IN NATURAL AND CLINICAL SCIENCE AND TECHNOLOGY (URNCST) JOURNAL Read more URNCST Journal articles and submit your own today at: https://www.urncst.com

\title{
Influence of Developmental $\Delta 9$-Tetrahydrocannabinol Exposure on Longitudinal Cognitive Flexibility and Neuron Morphology in the Prefrontal Cortex: A Research Protocol
}

\author{
Anthony Nguyen, BSc Student [1]*, Lucas J. Omazic, BSc Student [1]
}

[1] Department of Biomedical Sciences, University of Guelph, Guelph, Ontario, Canada N1G 2W1

*Corresponding Author: anthonynguyen094@gmail.com

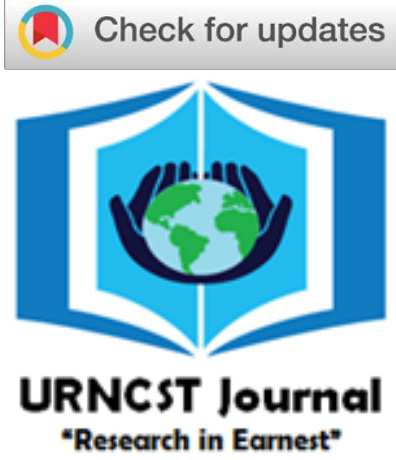

\begin{abstract}
Cannabis is one of the most commonly used substances during pregnancy. The components of cannabis are able to cross the placental barrier. Furthermore, perinatal cannabis exposure in affected offspring has been associated longitudinally with cognitive deficit in the form of attention. Therefore, we hypothesize that developmental $\Delta 9$-tetrahydrocannabinol (THC) exposure affects cognitive flexibility and leads to permanent neuron morphology changes in affected offspring. We propose to test these hypotheses in the offspring of 25 C57BL/6 THC-exposed pregnant mice by conducting a visual discrimination with reversal task (VDR) at post-gestational day 40 (P40), P80, P120 and a Golgi-Cox staining protocol at P140 in pyramidal cortical neurons of layer II/III and VI of the prefrontal cortex. The combination of this behavioural paradigm and the dendrite analysis for length, diameter and volume can provide insight on neurobiological consequences of perinatal cannabis and may lead to the development of therapeutic interventions in affected children.
\end{abstract}

Keywords: attention deficit; cognitive flexibility; developmental $\Delta 9$-tetrahydrocannabinol; neuron morphology; perinatal cannabis; visual discrimination with reversal task

\section{Introduction}

Cannabis is one of the most commonly used drugs during pregnancy [1]. The components of cannabis can cross over the placenta which raises health concerns for affected offspring [1]. Based on large correlational studies in humans such as the Ottawa Prenatal Prospective Study (OPPS), Maternal Health Practices and Child Development (MHPCD), and Generation R (GEN-R), an impairment of short-term memory and attention in early childhood was observed consistenly with cannabis exposure during the second and third trimester of pregnancy $[1,2]$. Studies have also shown an increase in impulsivity and hyperactive behaviour in affected offspring [4].

Despite these large-scale studies, current literature in understanding attention-related effects of perinatal cannabis has been mainly correlational [3]. Although it has been shown that developmental exposure to $\Delta$ 9-tetrahydrocannabinol (THC) has interfering effects in developing cortical neuron projections in mice [4], there is a gap of knowledge in understanding behavioural deficits and its relationship to permanent neuron morphology changes. Furthermore, developmental exposure to THC during certain trimesters of pregnancy and its effect on cognitive flexibility over time has not been thoroughly investigated.

Nguyen et al. | URNCST Journal (2020): Volume 2, Issue 4 DOI Link: https://doi.org/10.26685/urncst.174
We propose a research protocol that investigates the developmental effect of THC in a C57BL/6 mouse model. THC will be administered during different combinations of trimesters of pregnancy and the effect to behaviour and neuron morphology will be measured in affected offspring (Figure 1). Visual discrimination with reversal task (VDR) will be conducted at post-gestational days 40 (P40), P80, and P120. VDR consists of two phases. Animals are presented with visual stimuli that either leads to a rewarded or punishment. After learning these associations, the stimuli-reward relationship is switched and animals are measured on how quickly they can adapt to new conditions. This will establish an understanding of THC's direct effect on attention and learning. Then, neuron morphology data will then be collected at P140 in cortical layers II/III and VI for pyramidal neurons of the PFC using a Golgi-Cox stain which allows for visualization of $1-3 \%$ neurons throughout a histology slice [5]. The dendrite length, diameter, and volume of these neurons will be measured and a sholl analysis will be conducted. This will establish an understanding of how neuronal circuitry may be affected from perinatal $\mathrm{THC}$ and relate to specific behavioural changes in mice. We hypothesize that increased THC exposure during pregnancy will lead to decreased cognitive flexibility and altered neuron

Page 1 of 6 
UNDERGRADUATE RESEARCH IN NATURAL AND CLINICAL SCIENCE AND TECHNOLOGY (URNCST) JOURNAL Read more URNCST Journal articles and submit your own today at: https://www.urncst.com

morphology. These results may provide an understanding of the developmental effects THC can have on attention related behaviours over time as well as changes in neuron morphology in affected offspring.

\section{Methods}

\section{Animals and Groups}

The experiment will begin with 25 nulliparous pregnant C57BL/6 mice aged from P90-P150. Pregnant mice will be observed until there is visual confirmation of a vaginal copulatory plug. This is an indication of pregnancy where pregnant mice will be separated into individual cages. At this point, gestational day 1 (G1) will commence. All VDR and neuron morphology experiments will be conducted in affected offspring. Food and water will be provided ad libitum to the offspring and mother with the exception of testing days. On VDR testing days, food and water will be restricted until testing is completed. Cages will be maintained in temperature and humidity controlled rooms with a 12 hour light/dark cycle. Lights will be on at 8:00 PM and lights will be off at 8:00 AM. VDR will be conducted with the lights off at 9:00 AM daily as mice are nocturnal.

\section{Developmental Treatment Regimens}

There will be five groups of five pregnant mothers as shown in (Figure 1) which includes two control groups $(\mathrm{C} 1, \mathrm{C} 2)$ and three condition groups (T1, T2, T3). Therefore, five litters will be born per group and 1 male and 1 female will be randomly selected for use $(n=10,5 M \& 5 F)$. Pregnant mice and pups will be administered $20 \mathrm{mg} / \mathrm{kg}$ of THC via intraperitoneal injections. This dosage translates to $60 \mathrm{mg} / \mathrm{m}^{2}$ in humans which is below the maximum human recommended dose of synthetic THC [6]. The intraperitoneal injection method allows for greater bioavailability of THC than other methods of exposure [6]. Mice in the $\mathrm{C} 1$ group will receive saline injections rather than THC.

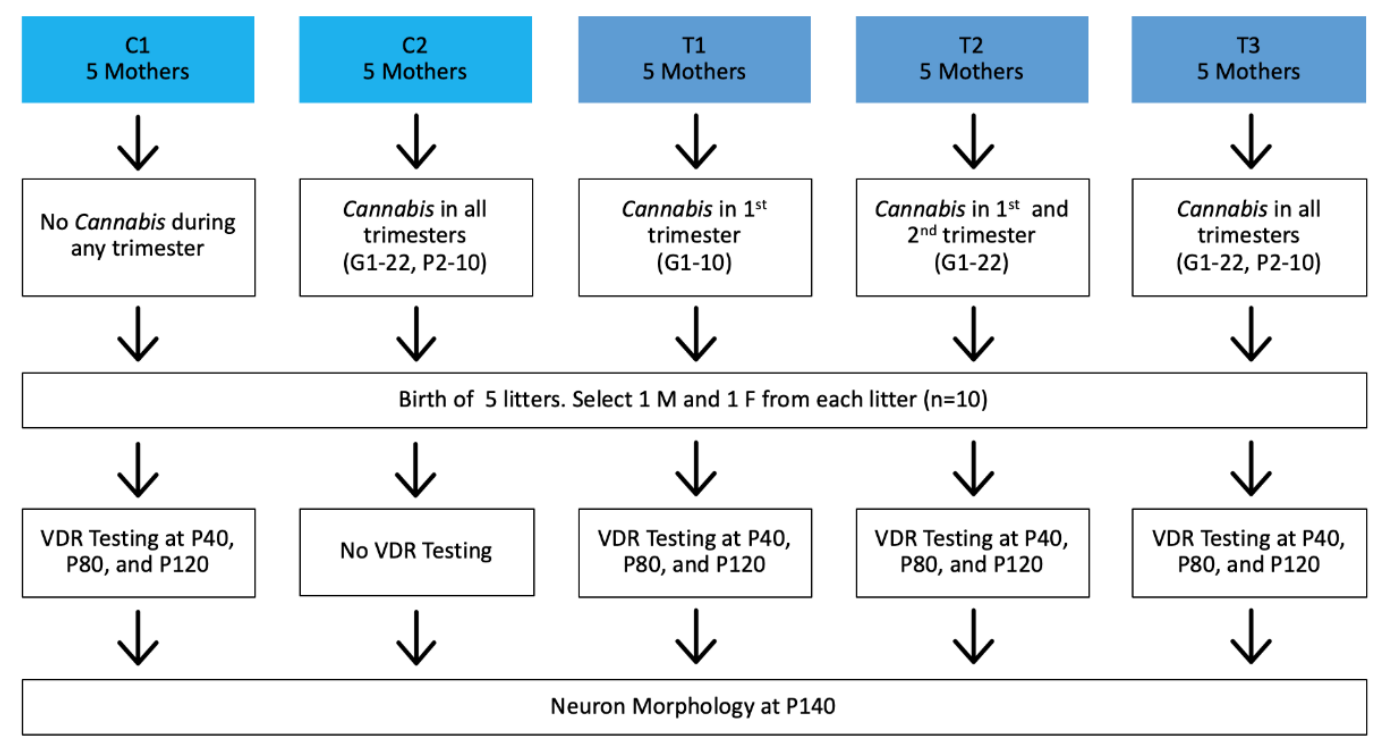

Figure 1: Outline of methodology for control and condition groups.

Humans have three perinatal trimesters during pregnancy which respectively correlate to gestational days $(G)$ 1-10, 11-22, and postnatal days (P) 2-10 in mice for their brain development [7]. C1 pregnant mothers will not be given THC. C2 will not undergo any VDR testing and will receive THC in all trimesters (G1-22, P2-10). Results between all groups except $\mathrm{C} 2$ may experience induced learning effects from VDR testing, however, this effect will be consistent among these groups and will enable us to compare learning behaviours with neuron morphology changes. Therefore, $\mathrm{C} 2$ will be a control to account for VDR testing effects on neuron morphology. It is possible that $\mathrm{T} 1$ will be given $\mathrm{THC}$ in only the first trimester of pregnancy (G1-10). T2 will be given THC in the first and second trimester of pregnancy (G1-22). T1 and $\mathrm{T} 2$ are representative of mothers who stop using cannabis after the first and second trimester of pregnancy respectively. T3 will be given THC in all trimesters of pregnancy (G1-22, P2-10). This is representative of mothers who do not stop using cannabis during pregnancy. C1, T1, T2, and T3 will undergo behavioural testing at 3 time points: P40, P80, and P120. This will measure longitudinal changes in cognitive flexibility. Offspring will be gonadectomized at P20 to avert variability of the estrous cycle and is done in both sexes to prevent confounding variables of surgical stress [8]. All groups will be euthanized at P140 and neuron morphology data will be collected. 
UNDERGRADUATE RESEARCH IN NATURAL AND CLINICAL SCIENCE AND TECHNOLOGY (URNCST) JOURNAL Read more URNCST Journal articles and submit your own today at: https://www.urncst.com

Visual Discrimination with Reversal Task
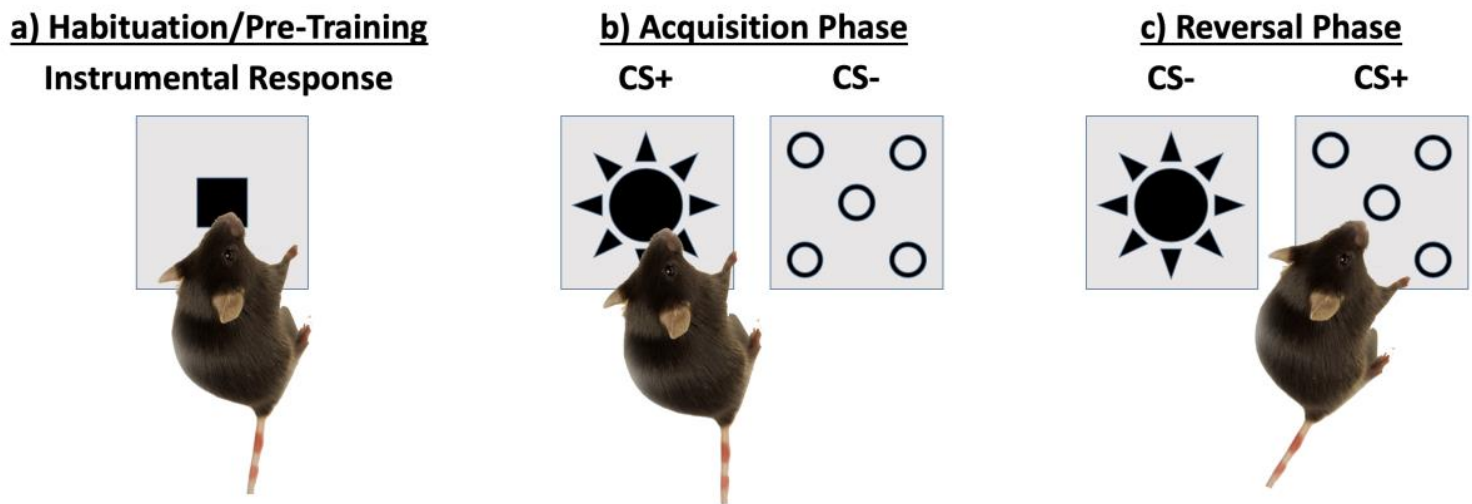

Figure 2: Visual Discrimination task acquisition and reversal phases. Mice are provided with a touchscreen interface where nose pokes on the CS+ result in a reward or nose pokes on the CS - result in a punishment. a) Habituation/PreTraining: Mice will undergo habituation in the testing chamber and learn how to make an instrumental response.

b) Acquisition phase: Mice must have an $80 \%$ success rate over 2 consecutive days pressing the CS+. c) Reversal phase: $\mathrm{CS}+$ and $\mathrm{CS}-$ are switched and performance levels are measured over 10 sessions with 30 completed trials.

VDR methods are adapted from Van den Broeck et al. (2019) [3]. Animals will be food-deprived during any VDR training or testing day until they complete their task. VDR is used to measure learning and attention which is mediated primarily by the PFC and involves two phases shown in (Figure 2). VDR chambers will be ventilated and will attenuate sound/light. Inside the VDR chambers, there will be two touchscreen interfaces, a dispenser for reward, and an infrared camera for experimental monitoring. The touchscreen device registers any sort of touch regardless of the amount of pressure through infrared photocells. Mice will undergo habituation to become acquainted with the test conditions and environment. Then, mice will undergo a pre-training phase where they will learn how to make an instrumental response. The image used on the touchscreen device will be different than those used during the acquisition and reversal phase. Upon three consecutive, successful responses, the acquisition phase will begin.

The acquisition phase will begin at P40, P80, and P120 and involves two images being shown on touchscreen interfaces. Mice will be rewarded for pressing one touchscreen image $(\mathrm{CS}+)$ with a small quantity of strawberry milk. Mice who press the other image (CS-) will be punished through a 15 second timeout and a mildly aversive tone, mice will be punished with a 15-second timeout where no reward will be given and will receive a mildly aversive tone for pressing the other image (CS-). Counterbalancing of the shown images will be done for each group. One trial will consist of a mouse's response to the shown stimuli. When 30 trials are executed or 60 minutes have elapsed, one session will be completed. Sessions occur daily until the mice perform 30 trials with an $80 \%$ success rate for two consecutive days. The ability to achieve the task will be measured to compare learning characteristics between groups. After learning the initial set

Nguyen et al. | URNCST Journal (2020): Volume 2, Issue 4 DOI Link: https://doi.org/10.26685/urncst.174 of conditions, the stimuli will be reversed and the mouse will be measured on its cognitive flexibility based on how quickly it recognizes the new conditions. This is called the reversal phase. Ten sessions will be completed and the \% of correct responses will be recorded. The ability to perform in the reversal phase will be measured to compare cognitive flexibility between groups.

\section{Golgi-Cox Staining}

Methods are adapted from Louth et al. (2018) [9]. After the completion of the third VDR testing at P120, mice will be euthanized at P140 and brains will be placed in a Golgi- Cox impregnation solution to study neuron morphology. Brains will be incubated in this solution for 25 days in the dark and then will be moved into sucrose cryoprotectant $(30 \%(\mathrm{w} / \mathrm{v})$ sucrose in phosphate buffer $(\mathrm{PB})$, $\mathrm{pH}$ 7.4) for 48 hours. Then brains will be stored at $-80{ }^{\circ} \mathrm{C}$ or can be sliced into $500 \mu \mathrm{m}$-thick sections with a vibratome. Sections of the PFC can be kept in $6 \%(\mathrm{w} / \mathrm{v})$ sucrose in PB overnight and fixed with $4 \%$ paraformaldehyde in PB for 10 minutes. Sections will be washed in water for 5 minutes twice, incubated in $2.7 \%(\mathrm{v} / \mathrm{v})$ ammonium hydroxide for 15 minutes, washed in water for 5 minutes twice, placed into Kodak Fixative A for 20 minutes, and washed in water for 5 minutes twice. Next, sections will undergo a dehydration process with ethanol $(100 \%, 95 \%$, $75 \%, 50 \%)$ and will be counterstained with $0.5 \%(\mathrm{w} / \mathrm{v})$ cresylviolet. Brain sections are placed on a microscope slide and coverslipped with paramount.

\section{Imaging of PFC Neurons}

Researchers during imaging or tracing will be blinded to the groups. Bright field imaging will be used with a silicone immersion objective. Neurolucida software must be used to capture high-resolution image stacks. 
All components of the neuron will be completely inside the brain slice to be included in the study. Two neurons from cortical layer II/III and 2 neurons from cortical layer VI will be selected randomly for each hemisphere $(8$ neurons per mice). Apical/Basal dendrites will be traced using Neuromantic software and analyzed using Neurolucida Explorer software for dendrite length, diameter, and volume.

\section{Statistical Analysis}

Ten mice each for $\mathrm{C} 1, \mathrm{~T} 1, \mathrm{~T} 2$, and $\mathrm{T} 3$ will be used for the VDR analysis. The acquisition and reversal phase will be presented as mean \pm SEM. T-tests will be used to assess general performance during both phases. A repeated-measures ANOVA will be used to measure significance in performance over time for both phases (number of trials and percentage accuracy). Statistical significance will be determined if $\mathrm{p}<0.05$.

Ten mice each for $\mathrm{C} 1, \mathrm{C} 2, \mathrm{~T} 1, \mathrm{~T} 2$, and $\mathrm{T} 3$ will be used for morphological analysis. Four neurons from each hemisphere of the PFC will be selected from each mice and traced (8 neurons per mice). Morphology measures of dendrite length, volume, and diameter for both apical/basal dendrites will be averaged and data will be presented as the mean \pm SEM. Sholl-analysis for dendrite length, volume, and diameter will be conducted afterwards. These morphology properties will be measured in concentric spheres that increase by a $25 \mu \mathrm{m}$ radius $(25 \mu \mathrm{m}$ radius steps). The main effect of condition and distance from soma will be subjected to two-way ANOVAs. Statistical significance will be determined if $p<0.05$.

Timeline of Experimental Procedure

\begin{tabular}{|c|c|c|c|c|}
\hline $\begin{array}{c}\text { Gestation } \\
(\sim 22 \text { Days })\end{array}$ & Life Cycle of Mice / Behavioral Testing & Golgi-Cox Protocol & Neuron Tracing & Data Analysis \\
$(\sim 50$ days $)$ & $(\sim 30$ Days $)$ & $(\sim 20$ Days $)$ & days $)$ \\
\hline
\end{tabular}

Figure 3: Timeline of experiment. This does not include pilot experiments or time to reconduct any experiments if needed.

\section{Results}

It is anticipated that this investigation will take 360 days to 540 days to complete. As (Figure 3) shows, the experiments and data analysis alone should take approximately 302 days to complete. This project would take multiple individuals to conduct the behavioural testing and neuron tracing.

\section{Discussions}

This research protocol suggests a methodology to understand the effect of THC on cognitive flexibility and neuron morphology in affected mice offspring. The proposed groups are expected to reveal the effects of THC during certain trimesters of pregnancy. T1 represents pregnant mothers who stop using cannabis after trimester 1 . T2 represents pregnant mothers who stop using cannabis after trimester 2 . T3 represents pregnant mothers who do not stop using cannabis regardless of their pregnancy.

With increased duration of THC consumption, we expect there to be greater attention-related deficits and alteration of apical/basal dendrite length, diameter, and volume in comparison to $\mathrm{C} 1$ offspring. During VDR, we expect $\mathrm{T} 3$ will likely perform the worst in the acquisition phase and reversal phase. Thereby, mice will take a longer time to acquire the task (more sessions) and will make a greater amount of errors when the CS+ and CS- are switched for all VDR testing periods (P40, P80, P120). The longer acquisition period and greater amount of errors during VDR will likely be attenuated slightly as mice age similar to previous correlational literature [4]. Furthermore, we expect neuron morphology in $\mathrm{T} 3$ to also have the greatest amount of altercation when compared to $\mathrm{C} 1$ in both PFC layers measured. Direction of the neuron morphology is unknown as no previous literature, to our knowledge, has explored changes in neuron morphology in the PFC in offspring affected from perinatal cannabis usage [1]. Furthermore, we expect $\mathrm{T} 1$ and $\mathrm{T} 2$ to have an intermediate effect between $\mathrm{C} 1$ and $\mathrm{T} 3$ for behavioural and neuron morphology analysis. Lastly, the $\mathrm{C} 2$ group plays an important control in our set of experiments. We can observe the effects of the behavioural paradigm on neuron morphology with this group. As all other groups will be undergoing behavioural testing, any neuron morphology differences measured will be relative to each other and will still play a role in understanding the effects of perinatal cannabis in affected offspring.

\section{Conclusions}

Current research on developmental cannabis exposure and attention has been mainly correlational in humans. To our knowledge, this research protocol is the first to address the need to understand the effects of developmental THC usage on cognitive flexibility over time and dendrite morphology in PFC cortical layers II/III and VI of mice.

The PFC is important for many cognitive functions. Alteration of the morphology can affect efferent signaling in this region which can underlie a variety of behavioural changes in affected offspring. Therefore, the results of this study may provide valuable insight on the neurobiological effects of developmental THC. Furthermore, this information may play a role in developing future therapeutic interventions in affected children. Future studies should investigate differences in neuron morphology at different ages in mice which correspond to the time points investigated for VDR 
UNDERGRADUATE RESEARCH IN NATURAL AND CLINICAL SCIENCE AND TECHNOLOGY (URNCST) JOURNAL Read more URNCST Journal articles and submit your own today at: https://www.urncst.com

in this study (P40, P80, P120). This will provide a comparison between behaviour and neuron morphology throughout development. Furthermore, whole-cell electrophysiology with biocytin-patch solution can be used to directly investigate a neuron's functional properties to its morphological properties. Another area of exploration is spine analysis for the same histology samples collected from affected offspring. This protocol may provide further information on the effects of perinatal cannabis and its health implications in affected offspring.

\section{List of Abbreviations}

C1, C2: Control groups 1 and 2

G: Gestational day

GEN-R: Generation R

MHPCD: Maternal Health Practices and Child

Development

OPPS: Ottawa Perinatal Prospective Study

P: Post-gestational day

PFC: Prefrontal cortex

T1, T2, T3: Condition group 1, 2, and 3

THC: $\Delta$ 9-tetrahydrocannabinol

VDR: Visual discrimination with reversal task

\section{Conflicts of Interest}

The authors declare that they have no conflicts of interest.

Ethics Approval and/or Participant Consent

This article did not require ethics approval and/or participant consent as it is a research protocol.

\section{Authors' Contributions}

AN, LO: conceived of the presented ideas and made substantial contributions to the design of the study, drafted and revised the manuscript critically, and gave final approval of the version to be published.

\section{Acknowledgements}

We would like to acknowledge Dr. Craig Bailey, Dr. Neil MacLusky and Dr. Jibran Khokar for their guidance with the manuscript and the development of methods. We would also like to acknowledge Jonathan Chung for the collaboration of the ideas in the paper and for general support.

\section{Funding}

This research protocol was not funded.

\section{References}

[1] Wu C-S, Jew CP, Lu H-C. Lasting impacts of prenatal cannabis exposure and the role of endogenous cannabinoids in the developing brain. Future Neurol. 2011; 6(4): 459-580. https://doi.org/10.2217/fnl.11.27

[2] McLemore GL, Richardson KA. Data from three prospective longitudinal human cohorts of perinatal marijuana exposure and offspring outcomes from the fetal period through young adulthood. Data $\mathrm{Br}$. 2016 Dec; 9: 753-57. https://dx.doi.org/10.1016/ j.dib.2016.10.005

[3] Van den Broeck L, Hansquine P, Callaerts-Vegh Z, D'hooge R. Impaired reversal learning in APPPS1-21 mice in the touchscreen visual discrimination task. Front Behav Neurosci. 2019 May; 13: 1-9. https://doi.org/10.3389/fnbeh.2019.00092

[4] De Salas-Quiroga A, Díaz-Alonso J, García-Rincón D, Remmers F, Vega D, Gómez-Cañas M, et al. Perinatal exposure to cannabinoids evokes long-lasting functional alterations by targeting $\mathrm{CB}_{1}$ receptors on developing cortical neurons. Proc Natl Acad Sci USA. 2015 Nov; 112(44): 13693-13698. https://doi.org/10.1073/pnas.1514962112

[5] Zaqout S, Kaindl AM. Golgi-Cox staining step by step. Front Neuroanat. 2016 Mar; 10:38. https://doi.org/10.3389/fnana.2016.00038

[6] Oza M, Becker W, Gummadidala PM, Dias T, Omebeyinje MH, Chen L, et al. Acute and short-term administrations of delta-9-tetrahydrocannabinol modulate major gut metabolomic regulatory pathways in C57BL/6 mice. Sci Rep. 2019; 9(1): 1-12. https://doi.org/10.1038/s41598-019-46478-0

[7] Patten AR, Fontaine CJ, Christie BR. A comparison of the different animal models of fetal alcohol spectrum disorders and their use in studying complex behaviors. Front Pediatr. 2014 Sep; 2: 1-19. https://doi.org/10.3389/fped.2014.00093

[8] Bowman R, Maclusky N, Sarmiento Y, Gordon M, Luine VN. Sexually dimorphic effects of perinatal stress on cognition, hormonal responses, and central neurotransmitters. Endocrinology. 2004 Aug; 145(8): 3778-3787. https://doi.org/10.1210/en.2003-1759

[9] Louth EL, Luctkar HD, Heney KA, Bailey CDC. Developmental ethanol exposure alters the morphology of mouse prefrontal neurons in a layer-specific manner. Brain Res. 2018 Jan; 1678: 94-105. https://doi.org/10.1016/j.brainres.2017.10.005 
UNDERGRADUATE RESEARCH IN NATURAL AND CLINICAL SCIENCE AND TECHNOLOGY (URNCST) JOURNAL Read more URNCST Journal articles and submit your own today at: https://www.urncst.com

Article Information

Managing Editor: Jeremy Y. Ng

Peer Reviewers: Bi-ru Amy Yeung, Jennifer Williams, Vinita Dhir

Article Dates: Received Nov 24 19; Accepted Jan 31 20; Published Feb 1220

\section{Citation}

Nguyen A, Omazic LJ. Influence of developmental $\Delta$ 9-tetrahydrocannabinol exposure on longitudinal cognitive flexibility and neuron morphology in the prefrontal cortex: A research protocol. URNCST Journal. 2020 Feb 12: 4(2).

https://urncst.com/index.php/urncst/article/view/174

DOI Link: https://doi.org/10.26685/urncst.174

\section{Copyright}

(C) Anthony Nguyen, Lucas J. Omazic (2020). Published first in the Undergraduate Research in Natural and Clinical Science and Technology (URNCST) Journal. This is an open access article distributed under the terms of the Creative Commons Attribution License (https://creativecommons.org/licenses/by/4.0/), which permits unrestricted use, distribution, and reproduction in any medium, provided the original work, first published in the Undergraduate Research in Natural and Clinical Science and Technology (URNCST) Journal, is properly cited. The complete bibliographic information, a link to the original publication on http://www.urncst.com, as well as this copyright and license information must be included.

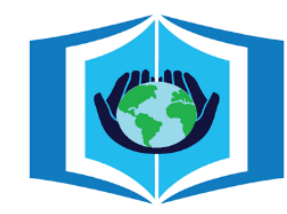

\section{URNCST Journal \\ "Research in Earnest"}

\section{Funded by the Government of Canada}

\section{Canadà̀}

Do you research in earnest? Submit your next undergraduate research article to the URNCST Journal!

| Open Access | Peer-Reviewed | Rapid Turnaround Time | International |

| Broad and Multidisciplinary | Indexed | Innovative | Social Media Promoted |

Pre-submission inquiries? Send us an email at info@ urncst.com | Facebook, Twitter and LinkedIn: @URNCST

Submit YOUR manuscript today at https://www.urncst.com! 